\title{
Synthesis and Characterization of Magnetoferritin
}

\author{
Z. Mitróová*, L. Melníková, J. KováČ, M. Timko and P. KopČanský \\ Institute of Experimental Physics, SAS, Watsonova 47, 04001 Kosice, Slovakia
}

\begin{abstract}
The paper presents detailed experimental study of synthesis and characterization a bioinorganic magnetic molecule - magnetoferritin. Magnetoferritin with loading of iron ions per protein molecule in the range from 300 to 3000 was prepared. Size distribution analysis (transmission electron microscopy, dynamic light scattering) shows spherical nanoparticles with particle size distribution from 2 to $12 \mathrm{~nm}$, and hydrodynamic diameter from 12 to $25 \mathrm{~nm}$. The thermomagnetic curves measured after cooling the sample in zero field (zero-field cooling) and under the presence of the measurement field (field cooling) show superparamagnetic behavior with the blocking temperature $T_{\mathrm{b}}$ from 22 to $60 \mathrm{~K}$ and the magnetization loops measured below $T_{\mathrm{b}}$ (at $2 \mathrm{~K}$ ) show the hysteresis with coercive field from 20 to $30 \mathrm{kA} / \mathrm{m}$ depending on the concentration of the magnetic nanoparticles.
\end{abstract}

PACS: 75.30.Cr, 75.50.Ee, 75.60.Ej, 75.50.Tt

\section{Introduction}

In 1992 , it was shown that the cavity of apoferritin, the empty form of the protein, can be used as a confined reaction vessel to synthesize nanoparticles of non-native compounds [1]. The first of these was maghemite, a ferrimagnetic iron oxide $\left(\gamma-\mathrm{Fe}_{2} \mathrm{O}_{3}\right)$. The resulting material has been, for this reason, named "magnetoferritin" [1-3]. Magnetoferritin is a protein capsule (apoferritin) with a structure close to spherical layer (inner and outer diameter of 8 and $12 \mathrm{~nm}$, respectively) filled with magnetic nanoparticles. Along with it, magnetoferritin proved to be a useful model system for studying the fundamental effects of magnetostatic interactions in nanoparticle assemblies. Magnetic nanoparticles grown in these biological moulds are usually rather homogeneous in size, free from aggregation and soluble in water. Other important advantages, especially for applications, are their biocompatible character (magnetic concentrating of anticancer drugs in tumors, magnetic resonance imaging, magnetic hyperthermia cell labeling, etc. [4-7]), and the possibility to process them in order to fabricate complex superstructures [8] and even ordered crystals [9, 10]. The paper presents detailed experimental study of synthesis and characterization a bioinorganic magnetic molecule magnetoferritin.

\section{Experimental}

Synthetic ferritin, i.e., magnetoferritin was synthesized from equine spleen apoferritin (Sigma-Aldrich). Aqueous solutions of $\mathrm{Me}_{3} \mathrm{NO}(0.07 \mathrm{M})$ and $0.05 \mathrm{M}$ buffer solution AMPSO (3-[(1,1-dimethyl-2-hydroxyethyl)amino]-2-hydroxypropanesulfonic acid) buffered to $\mathrm{pH} 8.6$ with $2 \mathrm{M} \mathrm{NaOH}$ were prepared. The buffer was deaerated for 30 min with nitrogen. Then $1.5 \mu \mathrm{M}$ solution of apoferritin (AF) in AMPSO was prepared and continued with

* corresponding author; e-mail: mitro@saske.sk deaeration for a further 30 min then it was hermetically closed and placed in a preheated $\left(65^{\circ} \mathrm{C}\right)$ water bath on magnetic stirrer until the contents were allowed to reach equilibrium. For the synthesis of magnetoferritin $0.1 \mathrm{M}$ ferrous ammonium sulfate was prepared with deaerated water. Gentle stirring was continued and aliquots of $\mathrm{Fe}(\mathrm{II})$ and $\mathrm{Me}_{3} \mathrm{NO}$ were added dropwise to the reaction solution using syringes. In general, each addition of $\mathrm{Fe}(\mathrm{II})$ was followed by a stoichiometric aliquot of $\mathrm{Me}_{3} \mathrm{NO}$ (3Fe(II):2 $\mathrm{Me}_{3} \mathrm{NO}$ ) and the solution left for $15 \mathrm{~min}$ before repeating the stepwise procedure. Finally it was dialyzed against distilled water for $24 \mathrm{~h}$ to remove free ions from reaction solution.

Product was determined spectrophotometrically (UV-Vis spectrophotometer SPECORD 40, Analytik Jena). The amount of iron was measured after $\mathrm{HCl} / \mathrm{H}_{2} \mathrm{O}_{2}$ induced oxidation of $\mathrm{Fe}(\mathrm{II})$ to $\mathrm{Fe}(\mathrm{III})$ and an addition of $1 \%$ ammonium thiocyanate by absorption measurement of the thiocyanate complex at $\lambda=450 \mathrm{~nm}$. The content of protein was detected by modified Bradford method at $\lambda=595 \mathrm{~nm}$.

The morphology and size distribution of the samples were determined with the transmission electron microscopy (TEM Tesla BS 500). The sample was dropped on a copper grid and dried in air. The hydrodynamic size was determined by Zetasizer Nano system from Malvern Instruments. Here, the fluctuations in the scattered light are analyzed to detect the diffusion of the molecules and deduct their hydrodynamic size. The magnetic properties of the samples were performed with a SQUID magnetometer (Quantum Design MPMS 5XL) up to $5 \mathrm{~T}$ in the temperature range 2.0-295 K. For all temperatures and fields, there were measured both the signal of the solution containing magnetoferritin (samples B-G) and the signal of the solution containing apoferritin (sample A - the empty protein shells) with the same protein concentration. After subtraction of the second signal from the first, we thus obtain magnetization values due only to the magnetoferritin cores. 


\section{Results and discussion}

The sphere that is formed by apoferritin is approximately $12 \mathrm{~nm}$ in diameter (Table). This is a rather large protein, yet despite its unusual structure it follows the size predictions for globular proteins quite well. The number of Fe ions amount per molecule (number $N$ ), hydrodynamic size and magnetic properties are summarized in the Table.

Summarization of the size distribution analysis.

TABLE

\begin{tabular}{c|c|c|c|c|c}
\hline \hline Sample & Number $N$ & $\begin{array}{c}\text { Hydrodynamic } \\
\text { diameter }[\mathrm{nm}]\end{array}$ & $\begin{array}{c}\text { Coercive field } \\
\text { at 2 K [kA/m] }\end{array}$ & $\begin{array}{c}\text { Magnetization at 2 K } \\
\text { and } 5 \mathrm{~T}\left[\mathrm{~A} \mathrm{~m}^{2} / \mathrm{kg}\right]\end{array}$ & $T_{\mathrm{b}}[\mathrm{K}]$ \\
\hline A & 0 & 11.76 & & & \\
B & 320 & 13.95 & 29.45 & 0.013 & 22 \\
C & 485 & 13.16 & 22.29 & 0.021 & 24 \\
D & 540 & 18.40 & 20.30 & 0.026 & 27 \\
E & 1250 & 16.25 & 23.48 & 0.037 & 26 \\
F & 1937 & 24.13 & 27.86 & 0.047 & 60 \\
G & 3023 & 655 (aggregate) & 25.47 & 0.073 & 176 \\
H & 2358 & 23.36 & $150[11]$ & $3.26[11]$ & $12[11]$
\end{tabular}

Hydrodynamic diameter is an effective diameter of the protein in water which includes all the water molecules attracted to the molecule. It depends not only on the size of the mineral core of magnetoferritin, but also on surface of the molecule. Hydrodynamic diameter is growing with the increase of number $N$. The sample with highest Fe loading (sample $G$ ) shows aggregation of molecules due to magnetic force between nanoparticles in protein shell. Sample H in Table represents native horse spleen ferritin. It is applied because of comparison with synthesized magnetoferritin. Ferritin is by the shape like magnetoferritin, but its magnetic core, which is structurally similar to the mineral ferrihydrite $\left(5 \mathrm{Fe}_{2} \mathrm{O}_{3} \cdot 9 \mathrm{H}_{2} \mathrm{O}\right)$, presumes different magnetic properties. The TEM analyzes only magnetic nanoparticles encased in the protein shell. It shows increase of magnetic nanoparticles with the increase of number $N$ in the range from $2 \mathrm{~nm}$ to $12 \mathrm{~nm}$. These results are in good agreement with the measured hydrodynamic size.

The magnetic measurements show superparamagnetism of prepared magnetic particles without hysteresis at room temperature. The thermomagnetic curves (Fig. 1) measured after cooling the sample in zero field (ZFC) and under the presence of the measurement field (FC) show superparamagnetic behavior with the blocking temperature $T_{\mathrm{b}}$ around $25 \mathrm{~K}$ for samples with the low number $N$ (samples B, C, D, E). For higher number $N$ the blocking temperature is smeared due to aggregation of the particles. The magnetization loops measured below $T_{\mathrm{b}}$ (at $2 \mathrm{~K}$, Fig. 2) show the hysteresis with coercive field from 20 to $30 \mathrm{kA} / \mathrm{m}$ depending on the iron loading. The magnetization undergoes a slow approach to saturation but it is not yet saturated at fields up to

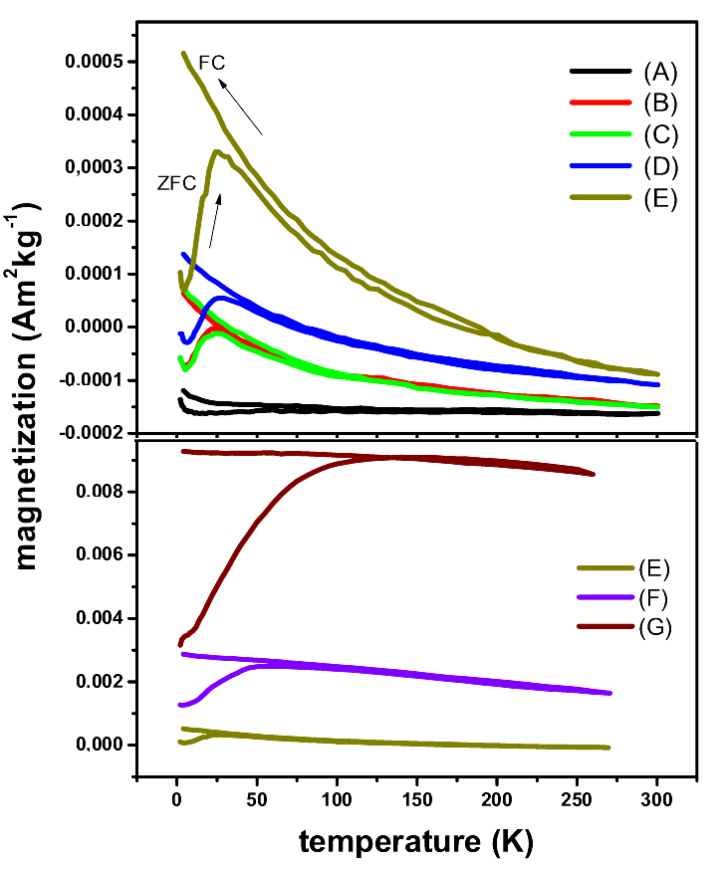

Fig. 1. The ZFC-FC curves measured at $10 \mathrm{mT}$.

$5 \mathrm{~T}$ which can be achieved. This result needs a further investigation.

The value of magnetization increases with increase of number $N$ as it is shown in Table. The high field magnetization measurements of related sample, native horse spleen ferritin, are published in [12]. The magnetic birefringence study of magnetoferritin is published in [13]. 


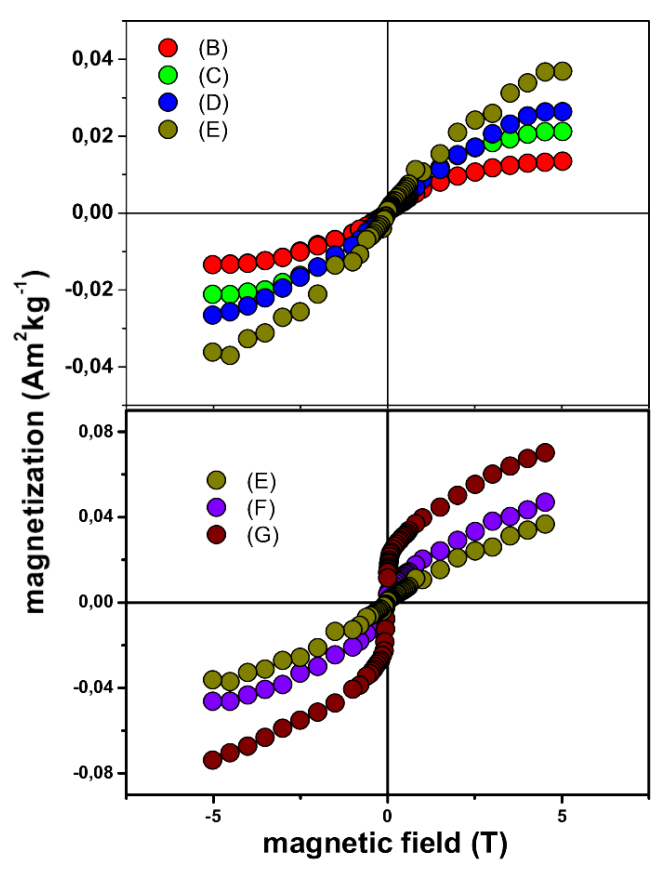

Fig. 2. The magnetization-field dependences measured at $2 \mathrm{~K}$.

\section{Conclusions}

We have prepared and characterized magnetoferritin with various iron loading per protein molecule. Size distribution analysis (TEM, dynamic light scattering (DLS)) confirmed spherical nanoparticles with particle size distribution from 2 to $12 \mathrm{~nm}$, and hydrodynamic diameter from 11 to $25 \mathrm{~nm}$. The magnetic measurements have showed superparamagnetism of prepared magnetic particles without hysteresis at room temperature and the hysteresis with coercive field from 20 to $30 \mathrm{kA} / \mathrm{m}$ depending on the concentration of the magnetic nanoparticles below $T_{\mathrm{b}}$ (at $2 \mathrm{~K}$ ). The thermomagnetic curves measured after cooling the sample in zero field (ZFC) and under the presence of the magnetic field (FC) show superparamagnetic behavior with the blocking temperature $T_{\mathrm{b}}$ around $25 \mathrm{~K}$ for samples with the lower loading of Fe. For higher loading of Fe the blocking temperature is smeared due to aggregation of the particles.

\section{Acknowledgments}

This work was supported by the Slovak Research and Development Agency under the contract No. APVV-0171-10, by the projects Nos. 26220120021, 26220120033 in the frame of Structural Funds of European Union, Centre of Excellence of SAS Nanofluid and VEGA 0077.

\section{References}

[1] F.C. Meldrun, B.R. Heywood, S. Mann, Science 257, 522 (1992)

[2] S. Gider, D.D. Awschalom, T. Douglas, S. Mann, M. Chaparala, Science 268, 77 (1995).

[3] K.K.W. Wong, T. Douglas, S. Gider, D.D. Awschalom, S. Mann, Chem. Mater. 10, 279 (1998)

[4] W. Wang, M.A. Knovich, L.G. Coffman, F.M. Torti, S.V. Torti, Biochim. Biophys. Acta 1800, 760 (2010).

[5] V.C. Jordan, M.R. Caplan, K.M. Bennett, Magn. Reson. Med. 64, 1260 (2010).

[6] A. Figuerola, R. Di Corato, L. Manna, T. Pellegrino, Pharmacol. Res. 62, 126 (2010).

[7] M.J. Martinez-Perez, R. de Miguel, C. Carbonera, M. Martinez-Julvez, A. Lostao, C. Piquer, C. Gomez-Moreno, J. Bartolome, F. Luis, Nanotechnology 21, 465707 (2010).

[8] M. Uchida, M.L. Flenniken, M. Allen, D.A. Willits, B.E. Crowley, S. Brumfield, A.F. Willis, L. Jackiw, M. Jutila, M.J. Young, T. Douglas, J. Am. Chem. Soc. 128, 16626 (2006).

[9] A. Soriano-Portillo, M. Clemente-Léon, C.J. Gomez-Garcia, E. Coronado, N. Galvez, E. Colacio, J.M. Dominguez-Vera, Synth. Met. 148, 7 (2005).

[10] O. Kasyutich, D. Tatchev, A. Hoell, F. Ogrin, C. Deewhurst, W. Schwarzacher, J. Appl. Phys. 105, 07B528 (2009).

[11] T.L. Xiang, C.Ch. Qian, L.Q. Song, P.Y. Xin, Chin. Sci. Bull. 55, 3174 (2010).

[12] R.P. Guertin, N. Harrison, Z.X. Zhou, S. McCall, F. Drymiotis, J. Magn. Mater. 308, 97 (2007).

[13] M. Koralewski, M. Pochylski, Z. Mitróová, M. Timko, P. Kopčanský, L. Melníková, J. Magn. Mater. 323 , 2413 (2011). 